\title{
A Legibilidade na Leitura da Poesia de Augusto de Campos como Agente de (Re)Escrita
}

Resumo: Na introdução de Outro (2015), Augusto de Campos afirma que "chegou muito tarde a um mundo muito novo", sendo esta uma resposta para a naturalidade com que o poeta participa no espaço virtual e digital. A persistente luta do "novo com o velho" é revisitada, testada e confrontada ao longo de todo o corpus poético de Augusto de Campos, experimentando intermedialmente novas formas de escrita e de leitura. Esta forma de estar tirou proveito dos meios de comunicação de massa para catequizar o grande público para as vanguardas literárias, deslocando a sua actuação da imprensa escrita para a internet e, em particular, para as redes sociais. É neste espaço multimedial que a intrínseca relação da forma visual e material com a poesia é explorada próximo do seu potencial máximo, justapondo elementos sonoros, visuais e temporais no lugar do verso. Neste artigo pretende-se explorar a relação da legibilidade com a forma macro e micro tipográfica, e com o processo de ler e reescrever o poema deste modo iterativo. Trata-se de uma exploração da linguagem que abre as possibilidades de materializar o sentido do texto no processo de interação, exploração e leitura do poema, ao invés de o explicitar verbalmente, num processo iterativo de natureza cognitiva.

Palavras-chave: Augusto de Campos, intermedialidade, transmedialidade, leitura, escrita, macrotipografia, microtipografia

Abstract: In the introduction of Outro (2015) Augusto de Campos claims that "he came too late to a new world". This is the natural answer to understand his fluency in virtual and digital scopes of creation. The persistent relation between "new and old" is revisited, tested and confronted all over Campos' poetic corpus, in which we find him experimenting new ways of writing and reading through intermediality. This approach has taken advantage of mass media to proselytize the general public about the literary avant-garde, extending his presence from the periodical press to the internet and, particularly, to social media networks. It is in this multimedia space that the intrinsic relationship of visual and material form with poetry is explored near its full potential, adding sound, visual and temporal elements to verse forms. This article aims to explore the relationship of legibility with the macro- and micro-typographic forms, and with the process of reading and re-writing the poem through these iterations. Readers are faced with an exploration of language which opens up the possibility of materializing the meaning of the text in the very process of interaction, exploration and reading of the poem (instead of making it verbally explicit), by means of an iterative process of cognitive nature.

Keywords: Augusto de Campos, intermediality, transmediality, reading, writing, macro-typographic , micro-typographic 
A poesia de Augusto de Campos é caracterizada pelo uso sistemático dos processos de espacialização e constelação da palavra escrita, permitindo a exploração de múltiplos sentidos de ver e ler o poema através da manipulação simultânea da macro e micro tipografia. Essa construção configura o poema concreto com uma orgânica própria que promove o engajamento do leitor para outras formas de ver e ler com base na experimentação, da rejeição do pré-estabelecido e recetividade ao novo, ao inédito e ao não-convencional. Claro é que a identidade de um texto concreto não pode rejeitar totalmente as convenções semióticas, sociais, gráficas, linguísticas, mas sim, procurar a oportunidade de derrubar essas fronteiras e encontrar outras formas de explorar a sensibilidade da palavra ou, noutros termos, a "materialidade da linguagem" (apud Amaral \& Filho 1985). Junta-se a essa tensão a ambição da instantaneidade, própria do mundo globalizado, adicionando a estética publicitária à poesia concreta e tornando líquidas as fronteiras literárias. "Disenfórmio" de Décio Pignatari (1967) e "Break-Up Cough" de Herb Lubalin (1956) são referências na exploração e esbatimento desses limites.

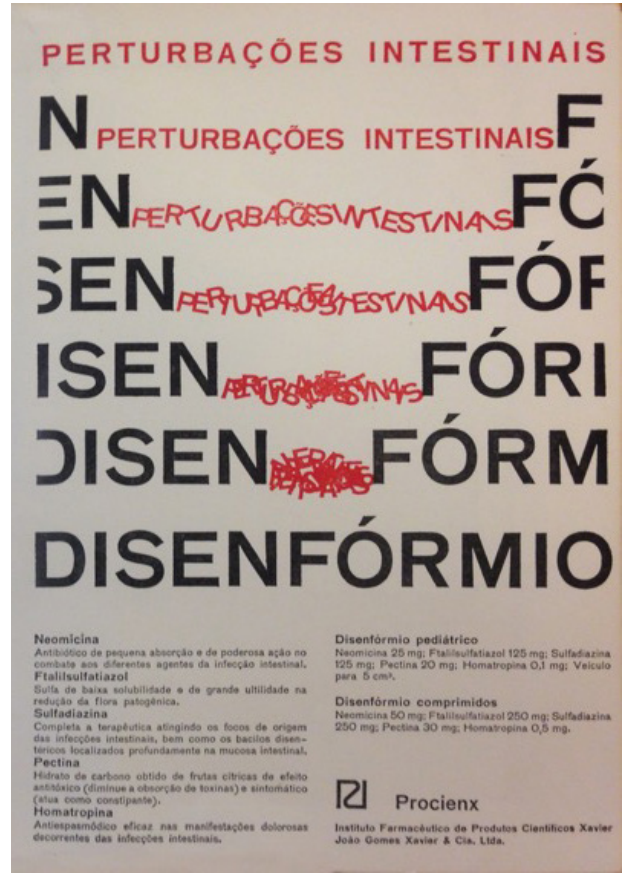

Fig. 1: Desinfórmio, Publicidade de Décio Pignatari na 5. ${ }^{a}$ edição da Revista Invenção (1967).

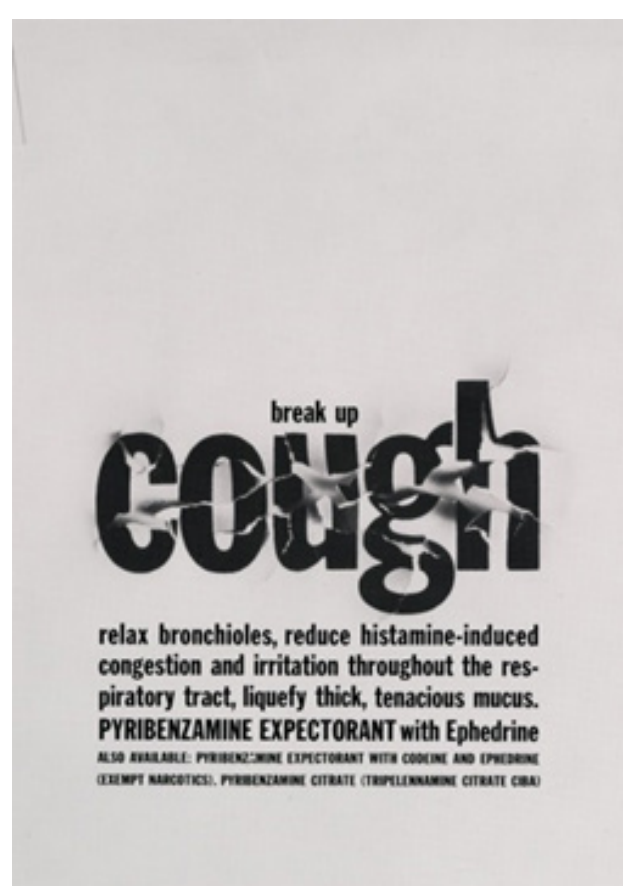

Fig. 2: Break up cough, Publicidade de Herb Luballin de 1956.

É um trabalho que tanto se faz pela "intervisualidade como processo de construção, de reprodução ou de transformação de modelos” (Plaza 2003: 11), conjugando-se a criação contemporânea com o que fora criado e está presente nos arquivos. Explora-se a 
duplicidade do novo e do velho, colocando em evidência o isomorfismo gráfico-espacial da página como elemento estrutural, expandindo a expressão da poesia concreta para além do poder da linguística e da tipografia (Mayer 1996: 96). Graças a essa base construtiva é possível ao poema expressar-se usando apenas signos gráficos ou recortes de revista, tornando permeáveis as fronteiras dos espaços literários com os espaços das demais artes ou mesmo do espaço urbano, ocupando o espaço da publicidade, sendo que o uso de cada um dos espaços implica uma consciência crítica sobre a questão material, bem como dos paradigmas de comunicação e metaforização de cada meio.

A origem do termo "poesia concreta" não é consensual. Várias fontes apontam para a sua primeira utilização em 1944 em Itália por Carlo Belloli (Solt 1971: 8) e na Suécia em 1953 por Öyvind Fahlström (1952). Contudo, é commumente aceite que o movimento é iniciado por Augusto de Campos, em 1955, num artigo na revista Fórum n. 3 ao publicar os poemas "Estrutura" e "Ideograma” (Süssekind/ Guimarães 2004: 13), ato enquadrado no movimento concreto internacional, possibilitado pelo estreito contacto de Décio Pignatari com Eugen Gomringer e, indirectamente, com Max Bill.

A Poesia Concreta Brasileira distingue-se no seio do movimento concreto global pela sua estética pop e pela exploração do carácter da tipografia (Hatherly 1975: 140), reflectindo a incorporação de postulados do campo das artes visuais e dos ideais do Plano Piloto de Brasília (Aguilar 2005: 74). Oficiosamente, o início do movimento concreto Brasileiro e o abandono do "verso e a sintaxe convencional" (Süssekind/ Guimarães 2004: 12) iniciou-se em 1953, abrindo a fase ortodoxa de composição matemática, com Poetamenos (composto em 1953, primeira edição em 1955, segunda edição em 1973, já usando fotolitos), num desafiante exercício de composição, impressão e leitura.

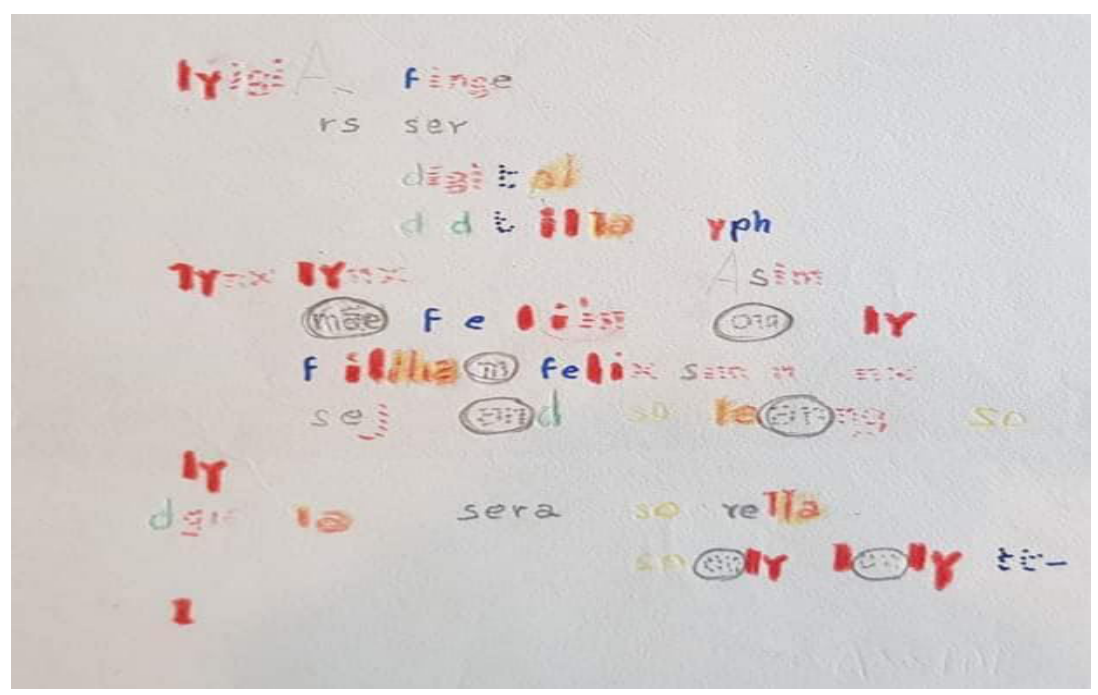

Fig. 3: Rascunho do poema “lygia fingers" (Campos 2019: 113) 
A história da produção da série de poemas poetamenos é fundamental para percebermos o grau de inovação que a composição tipográfica empregue trouxe à data. Neste período não era comum a impressão de planos com mais do que duas cores, nem tão pouco proliferaram pela América Latina tipos da geométrica letra "Futura", introduzida no sub-continente poucos anos antes (Eisele et al. 2017: 493), tornando a escolha do impressor certo para aquele trabalho um desafio considerável.

O processo de produção gráfica da série de poemas é incomum. Além da precisa e consciente operação tipográfica, privilegiava-se o funcionalismo, sem adornos, da tipografia (Campos 1994: 108). ${ }^{1}$ Nessa obra foi necessário fazer um trabalho tanto exímio como de improviso, dado que o impressor só tinha experiência na execução de documentos fiscais e pela primeira vez imprimia um livro de poesia (Campos 1994: 112). A cor foi conseguida pela execução de máscaras de cartão improvisadas a que cada uma correspondia a uma das seis cores presentes em cada plano (Campos 1994: 112). Esta primeira tiragem da série foi incluída no segundo número da Revista-Livro Noigandres 2 de $1955 .{ }^{2}$

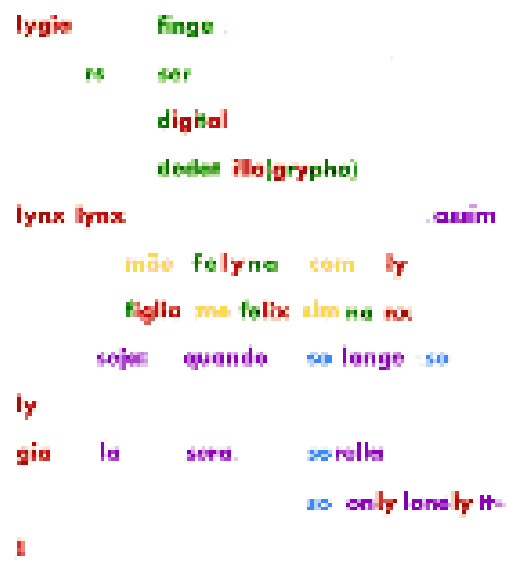

Fig. 4: Rascunho do poema "lygia fingers".

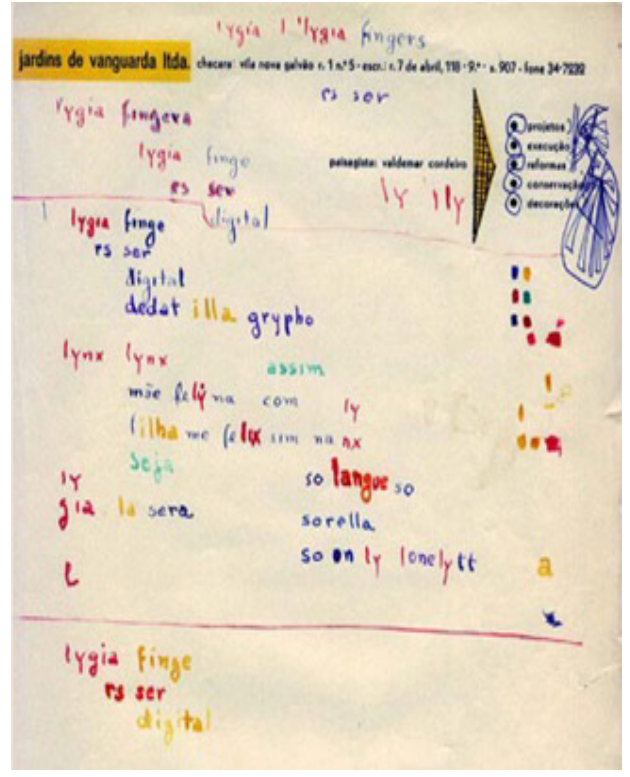

Fig. 5: Rascunho do poema "lygia fingers".

O resultado é um poema livre em função das possibilidades da geometria que liberta o leitor dos sentidos de leitura tradicionais. Não indica, nem pode especificar, o início da leitura, restando ao leitor a tarefa de instintivamente seguir o sentido lógico da 
conjugação de letras e palavras. O restante processo de significação vem pela cor, que respectivamente informa e comunica na ambivalência do tom e da semiótica que podemos associar a cada palavra, e pelo espaço que pautadamente define o ritmo de leitura como uma escala musical.

Em Poetamenos Augusto de Campos inicia a natureza intermedial da poesia concreta. Quer-se a "representação gráfica em cores (...), possibilite ao poema o funcionamento como "uma melodia contínua deslocada de um instrumento para o outro, mudando constantemente sua cor" (Campos 1973). ${ }^{3}$ Dessa forma Augusto de Campos transfere o domínio da sintaxe das palavras para a composição gráfica, omitindo a temática em prol do conjunto das unidades linguísticas e da forma como é possível extrair musicalidade das frases, palavras e sílabas, "como se [estas] fosse[m] instrumentos de uma orquestra" (Bollobas 2018).

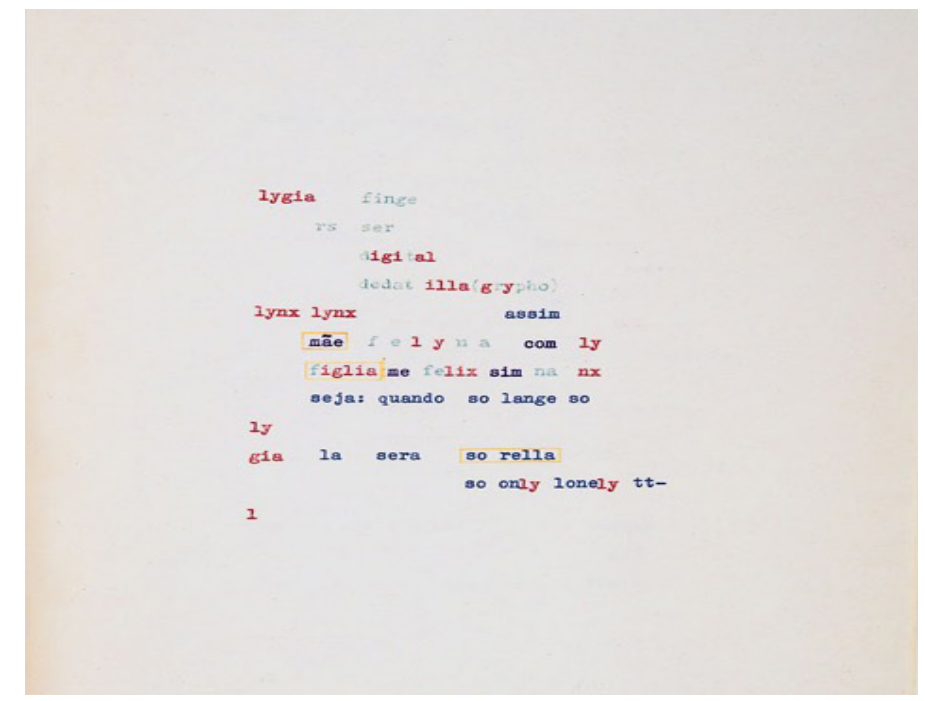

Fig. 6: Dactiloscrito do Poema "Lygia Fingers"

Neste jogo de leitura promove-se além do verbo, o sonoro e o visual, verbivocovisual, mas mais do que isso o confronto entre as práticas literárias tradicionais com os novos meios que se ansiavam explorar ("mas luminosos, ou filmletras, quem os tivera!) (Campos 1973), permitindo que a poesia quebrasse as fronteiras dos espaços literários tradicionais para participar além dos espaços das galerias e museus, também no espaço urbano, potenciando o texto cinético e o livro livre através do diálogo com a tecnologia (Campos 94: 110-111). Um caminho que, segundo Timo Ikonen, reabilita a poesia como "discurso falado" a partir do sujeito poético (2003). É um reforço da verbivocovisualidade da poesia concreta na medida em que é a partir da luz que se incute o movimento da letra que forma o poema, disposto numa forma parcial ou total, num movimento virtual 
(Ikonen 2003). A luz guia o espectador num caminho que transforma o leitor num elemento chave do processo de significação (Aguilar 2005: 304), ao longo de um processo cognitivo que o transformará pela experiência de ler, ver e de se ouvir durante o seu confronto com o poema.

A visualidade e a participação regular nos espaços das artes visuais acabou por colocar em evidência as componentes material e visual da poesia concreta, preterindo a sua sonoriedade. Esta é composta num exercício exímio da operação tipográfica, indicando e deixando em aberto os sentidos e de leitura em virtude das opções e de composição e da tipografia. O lugar e a escolha de cada caracter são pensados em função do tempo e ritmo de leitura que cada poema exige, promovendo a semantização de outros elementos materiais além da linguagem verbal.

A tipografia e o design assumem um papel importante na forma como absorvem ou activam a semântica da Poesia Concreta, substituindo ou reforçando as figuras de linguagem através dos seus traços, explorando a maleabilidade do texto o que permite que o significado do texto seja tão fluído quanto é a forma de leitura. É em função do tamanho do suporte de inscrição que se tomam escolhas macro tipográficas que definem o formato da impressão, o tamanho das colunas, as hierarquias de informação, operando nessa área as decisões micro tipográficas, definindo-se as formas das letras, os entrelinhamentos e espacejamento entre letras, entre palavras, goteiras, em prol da optimização da experiência de recepção do texto, nomeadamente optimizando a legibilidade e a leiturabilidade do texto (Hochuli 2009: 7) e, na simbiose destas opções, o espírito visual do texto.

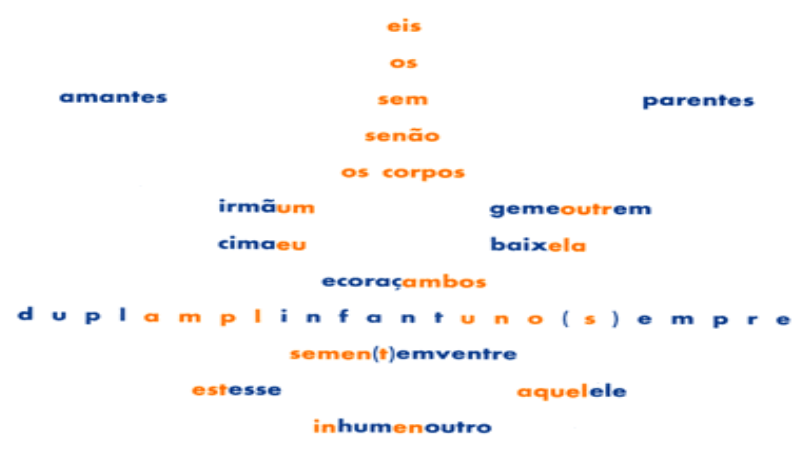

Fig. 7: A disposição mais conhecida do poema "eis os amantes" (Campos 1973) 
Numa perspectiva funcional, a tipografia transforma o espaço vazio num espaço comunicativo. Em função das técnicas de composição, a tipografia pode promover a legibilidade e a leiturabilidade, possibilitando a transmissão de uma mensagem de forma clara (Erlhoff/ Marshall 2001: 410) e inequívoca. Estes são factores que interferem na comunicação num nível superior ao da decifração dos signos e da junção silábica, que formulará a cada palavra e das palavras uma frase até chegarmos ao parágrafo e ao conjunto de texto. O texto na sua composição, seja esta clássica ou arrojada, tem igualmente expressão visual, e dessa composição obtêm-se formas de aceder ao texto como uma experiência de ler.

O poema concreto apresenta-se em semi-transparência, sendo o acesso à mensagem tanto imediato, como se adensa a cada re/leitura na medida em que o leitor aprende e apreende as formas de ler que conduzem ao significado do texto. ${ }^{4}$ Este percurso é modelado pelos contextos culturais, sociais e políticos que condicionam a aquisição de competências sociais, humanas, técnicas, entre outras, influenciando a forma como o leitor compreende o mundo (Mitchell 2005: 261). São estas capacidades cognitivas que permitem ao leitor interagir com a materialidade da literatura e percebê-la além das estritas convenções literárias. Quebrando-se a convenção é possível encontrar a significação em várias camadas de significação, viajando-se para além da pequena parte do que se pode extrair do imediato no poema. Assim, olhando-se para outras e novas formas de ler, possibilita-se a compreensão e o uso expressivo da tipografia numa lógica tanto expressivo-funcional como de proximidade com a exploração espacial de Mallarmé (Campos 1956: 32) ou cummings, bem como do ideograma, a junção asiática do texto e imagem para transmitir uma ideia explorada por Fenollosa e Pound.

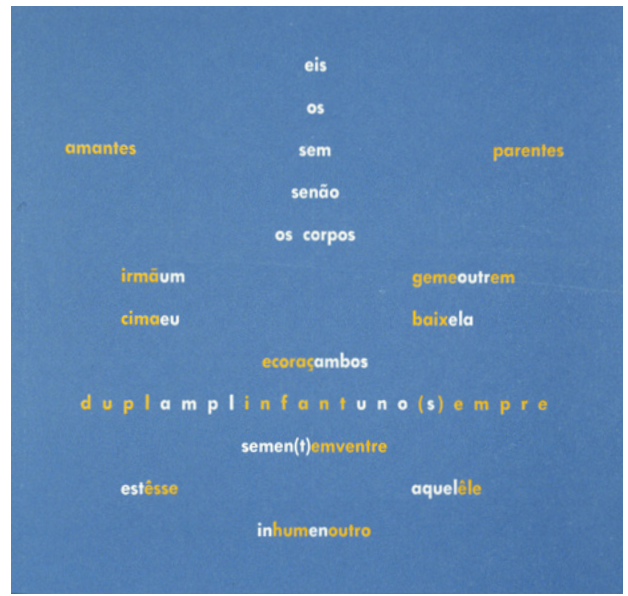

Fig. 8: versão colorida de “Eis os Amantes” (Solt 1971)

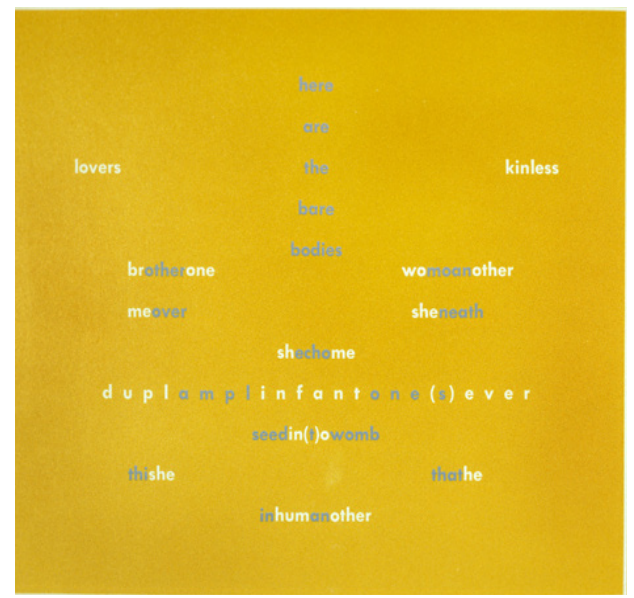

Fig. 9: Tradução em inglês de "Eis os Amantes" (Solt 1971) 
No leque de mediadores de uma obra impressa, como acontece em Poetamenos, o texto e a sua forma visual são mediados pelas opções de design; o papel, a encadernação, a disposição do conteúdo, a cor e outras opções gráficas com implicações semióticas e a tipografia, que interfere directamente com a leitura activando as várias camadas de significação verbivocovisual (Portela 2003: 3). Na obra de Augusto de Campos, em particular, verifica-se uma exploração recorrente do lema de Ludwig Mies van der Rohe "less is more" como ponto de chegada ao conteúdo. Vive-se uma fase de grande disrupção e confronto da poesia concreta com o panorama literário Brasileiro, distanciando-se "da poesia feita pela Geração de 45, dita como a terceira geração modernista de 22, assim como dos apelos expressivos de uma poesia focada na mensagem, no conteúdo" (Campos 2019: 111), como defenderão, alguns anos depois, os Neo-Concretos. É evidente o esforço colocado na experimentação e reconceptualização do material literário aproximando-o de processos matemáticos e de rigor geométrico. Esse processo de experimentação valoriza o processo criativo da poesia concreta, promovendo os mesmos ideais do grupo Ruptura na medida em que "o conteúdo não é o ponto de partida, mas o ponto de chegada" (Cordeiro 1956: 216).

Após o "Rei Menos o Reino", em que já explorava técnicas de montagem linguístico-sonora, Augusto de Campos promove o "menos" como a sua marca poética de estar, pela recusa ao cânone e ao tradicional em prol de uma outra forma de ver, sentir e explorar a linguagem poética, adoptando a margem como campo de expansão. Uma antinomia que deriva da antropofagia criando a antipoesia, opondo-se às normativas literárias populares (Campos 1966: 66; Campos 1967: 106), que conta com o leitor como elemento activo do processo criativo. O leitor assume a função de criador-crítico, numa "leitura comprometida", relacionando as formas ready-made dos poemas com a sua cognição seja sobre os contextos próprios do objecto ou o seu conhecimento do mundo (Shellhorse 2017: 90-91). Deste modo, a leitura é um processo transformador do indivíduo na medida em que este apreende outros mundos, vivências e perspectivas, expandindo-se o campo semântico das palavras enquanto elementos abstractos. A forma assume-se como uma "aglutinação de expressões" que interage com o suporte medial, subvertendo a semântica convencional com a condição de que com cada signo, frase e medium atingiu um estado de excesso de significação (Shellhorse 2017: 194-7) permitindo a veiculação de sentido de cada palavra tanto de forma isolada, como agrupada em constelação. A semântica emanada pelo ready-made, a exploração não-linear dos limites da literatura ou a contra-fabricação do presente, deslocando os contextos do mundo real para o plano poético, tornam a sua poesia um risco que não está, com facilidade, ao alcance de todos (Shellhorse 2017: 93-95).

Na série Poetamenos, Augusto de Campos coloca no sujeito poético a sua visão pessoal e íntima (cf. Campos 2019: 109), negando a "procura da objectividade desejada pelos concretistas" (Williams 1986: 6). "Lygia Fingers", homenagem do poeta Augusto à sua esposa Lygia, coloca todas as palavras com o mesmo grau de importância ${ }^{6}$ 
combinando-as e explorando-as verbivocovisualmente (Williams 1986: 7), permitindo numa primeira instância uma leitura linear que depois se desdobra nos vários sentidos do plano (Campos 2019: 109). Além da exploração do plano, da tipografia e dos sentidos de leitura, deve-se olhar para a carga semiótica das cores que conferem ao poema uma pluralidade de sentidos semânticos, visuais e sonoros (Süssekind/ Guimarães 2004: 12). Dessa forma, a cor vermelha, quente, associada ao sangue, ao sensível (Heller 2015: 35), ao perigo, ao luxo e à vivacidade (idem: 107) destaca a homenageada. A cor vermelha instintivamente nos conduz face às restantes 4 cores, contribuindo estas para a pluri-significação das palavras e do poema. A leitura linear do poema permite acompanhar o tom, musical e emocional, e a relação entre os elementos presentes no texto. As cinco vozes, cores e línguas, unem-se, potenciando, pelas relações do seu conjunto, o valor atomizado de cada palavra (Williams 1986: 8).

Opticamente o vermelho de 'Lygia' sobressai face às outras cores concretas, dando-nos o ponto de partida da leitura do poema. Ela transfigura-se. 'Lynx' plurissignifica-a desde a forma da perigosa felina até à constelação, permitindo a sua omnipresença ao longo de todo o ideograma, apresentando-se em grifos de forma ordenada, desordenada ou abreviados. A abreviação de Lygia amplia a interpretação, sendo ‘ly' acrónimo de love you. Lygia, de vermelho, conjuga-se salutarmente (Heller 2015: 39) com a esperança de cor verde. É nesta cor que surgem a maioria das formas verbais ('finge', 'ser', 'dedat', 'grypho', 'felix'), promovendo as relações predicativas que inscrevem Lygia no acto de escrever - grifar e datilografar (apud Perloff 2010: 68) - numa união progressiva com o sujeito poético em que o sentimento se transforma de perigosa 'felyna' até 'figlia' que o abona de felicidade ('felix'). É nessa relação entre cores e palavras que se sente o sentido do texto, sabendo que o verde transmite ora um "efeito venenoso ao lado do violeta" (Heller 2015: 39), presente na 2. ${ }^{a}$ parte do poema (Pondian 2005: 6), como promove a esperança "junto do azul e do amarelo" (Heller 2015: 39) que ladeia as palavras "felix" e "felyna". Visualmente o amarelo define a fronteira entre as duas partes do poema. As palavras “mãe”, “com”, “me”, "sim”, coloridas pelo optimismo e riqueza (Heller 2015: 185187), contrastam com a expressão predominante da segunda parte, a solidão e a tristeza (Pondian 2005: 6), mas também do perfil confiável, inteligente e tranquilo emanado pela cor azul, e da "união" e "sensualidade" proporcionada pelo violeta (Heller 2015: 35, 36). ${ }^{8}$ Segundo Eva Heller, na Idade Antiga, o violeta, por ser uma cor gerada pela luz, era símbolo de eternidade, poder e riqueza, do feminismo ou ainda "a cor que fica entre a vida e a morte" (cf. Heller 2015: 195, 206, 460, 210).

Em perspectiva complementar, a análise filológica da segunda parte do poema, onde se lê o trecho "seja: quando so lange so \la sera sorella \so only lonely tt-" vai ao encontro do que a análise cromática nos aponta, tornando-se evidente essa fantasia da união e de um projecto conjunto. 'Lange' é uma forma verbal de origem francesa que remete para os cuidados com os recém-nascidos, especificamente a troca de fraldas e o swaddling. ' 'So lange', tem dupla significação como mártir. Mártir da pureza ${ }^{10}$ ou "musa- 
-mártir" do modernismo de 22 (apud Campos 2014: 23), sendo ‘so lange soll' um pseudónimo da poetisa Patrícia Galvão"1 (Pagú), realizando-se a evocação intertextual a "O Sol por Natural”, em que a paixão "ses vezer" (Perloff 2010: 68) se esbate pelo confronto com a "natureza morta" (Neves 2005: 143).

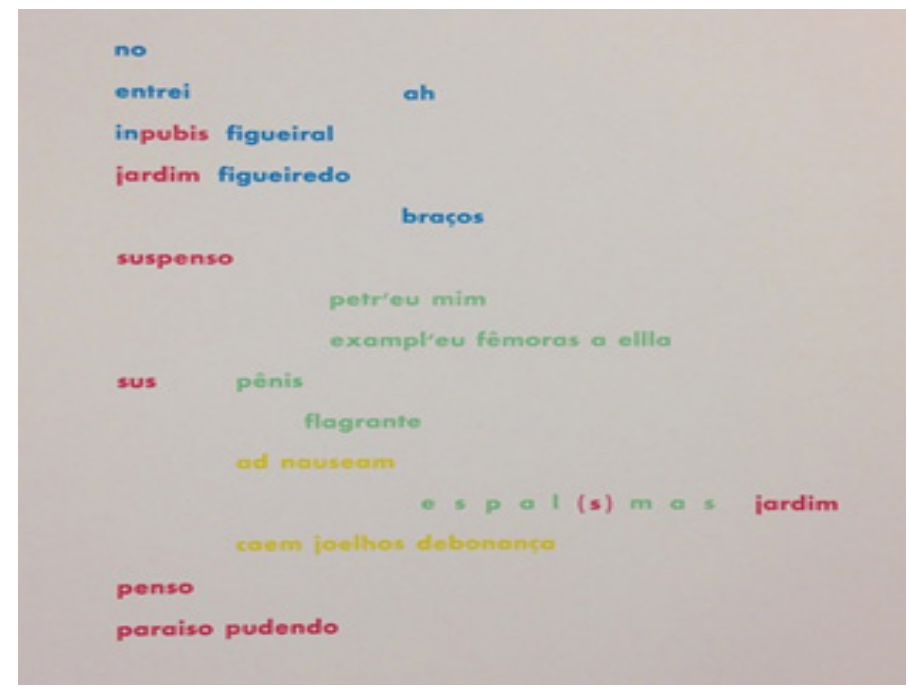

Fig. 10: Paraíso Pudento, o segundo poema de seis da série Poetamenos, "sensorializa" o amor espiritual na fenomenologia sexual por oposição a uma "visão puramente platônica” (Campos 09: 128)

O final do poema termina com o anoitecer, o fim do dia ou fim de um ciclo, passando a paixão a philia, "gia la sera sorella", numa alusão clara à passagem do tempo da vida em comunhão com Lygia, em que sem esta o sujeito poético ficará "so only lonely", suspirando seu nome "l” (Perloff 10: 68). A leitura atomizada não contribui para a interpretação uma vez que sós formam 'on' e 'lone', funcionando a primeira palavra como preposição, situando no espaço, ou advérbio, situando no tempo, e a segunda como adjectivo que remete para a solidão, para o ermo, desabitado ou ainda o pessimismo de uma possível viuvez, perdendo a sua 'rella', do latim rēgula, que o orienta e superintende. A constelação apesar de encaminhar o leitor para um percurso de leitura linear, promove as bases do ideograma, na conjugação da forma, das línguas, das cores e dos tons, pluralizando a semântica do poema enquanto Lygia, personagem central, rege o poema e alterna entre um conjunto bem distinto de papéis: “mãe, 'figlia', 'lynx', 'sorella'”12 (Dick 2002: 146), mas um conjunto de ações desempenhadas em função da exploração espacial do plano que se relacionam em primeira instância com o acto de se es/ins/crever ('dedat', 'grypho'), e, em segunda instância, de se entregar ('finge') (cf. Bollobás 2018), consolidando verbivocovisualmente o poema numa única letra, o seu único desejo, 'l'.

"Lygia Fingers" e "Eis os Amantes" são poemas em "consonância” pela temática 
"essencialmente lírica, onde há a permanente exibição dos sentimentos e das expressões íntimas de um sujeito poético" (Vasconcelos 2015: 81). Em conjunto com "paraíso pudendo", apresentam uma "conotação altamente erótica" (Williams 1986: 3) revelando um "descascamento fenomenológico do sentimento amoroso" (Campos 2009: 128), em que o corpo desnudado se "equipara à alma do corpo" e a representação "poético-gráfica do ato sexual" (Williams 1986: 9) traduz a "materialização das almas (...), uma reconciliação de espírito e matéria" (Campos 2009: 128) de ambos os elementos do casal. ${ }^{13}$

"Eis os Amantes" é uma encenação espacial e cromática de uma relação amorosa, explorando o conceito de fanopeia, de Ezra Pound, ao se afigurar como um pavão cortejando uma fêmea. A sua estrutura verbal é sustentada por várias palavras-valise que reforçam a união do casal (Silva 2008). "Eis \os \amantes sem parentes \senão \os corpos" imediatamente remete para o isolamento carnal, a união de dois sexos, que se verifica na aglutinação "irmãum" criando o irmão a partir da palavra irmã, o masculino a partir do feminino (Williams 1986: 10). O núcleo do poema formado pela quadrangulação "irmãum gemeoutrem \ cimaeu baixela” possibilita um leque alargado de leituras combinatórias que mecanicamente se reforçam e apresentam a "palavra como o corpo do outro" (Silva 2008), palavras essas em liberdade que se combinam e se unem, a sós, até não haver espaço que as separe. Essa ambiguidade possibilita um conjunto de leituras secundárias em que o sujeito poético, identificado pela cor laranja, tem "um outr \ eu [em] ela”, enquanto, ela, “irmã geme em \ cima eu baix[d]ela”. Esta “'tensão' central explode de sentidos terminando em escoraçambos, a fusão de 'escorçar' e 'ambos', reforçando a imagem da união amorosa e física” (Williams 1986: 10). Uma fusão sintática que une e remete para a mudança de percepção da dimensão do mundo quando estes amantes se encontram sem parentes(es), em que as prioridades se esbatem e o seu mundo os absorve, contrastando com a expansão dupla espacejada expressa a seguir em que o casal se assume 'duplamplinfantuno(s)empre', para (s)empre uma dupl(a) infant, extenso uno. Uma relação amistosa, fraterna, existente desde sempre, com ares pueris, dialogante com "Lygia Fingers" em que ela é "comparada a mãe, filha e (...) irmã", homenageando o companheirismo da sua amada (Vasconcelos 2015: 82-83).

Cromaticamente "Eis os Amantes" apresenta-se disposto sobre um eixo central de exótico e versátil laranja (Heller 2015: 403), que remete para a fertilidade, ${ }^{14}$ o deleite, ladeado do azul ciano da censura, da paz e humanidade, e da nobreza (Heller 2015: 103, 105, 107). Assim, é encontrado um ponto de equilíbrio e complementaridade,${ }^{15} \mathrm{em}$ que o prazer, o perigo, a recreação, o social e o "puro sabor" (idem: 407) é contrabalançado com a espiritualidade, a reflexão e o silêncio. Semen(t)emventre une as características cromáticas e a sonoridade das palavras criando uma sugestão morfêmica em que as cores opostas "reforçam a ideia da atração sexual" (Williams 1986: 12) e da fecundidade (Vasconcelos 2015: 85). A mesma autora acrescenta que a complementaridade das cores corrobora a ideia de "dependência e complementação entre os amantes, em sua relação enquanto casal” (2015: 82). A sua união é figurada simultaneamente como visualização 
da ejaculação e como processo reprodutivo criador.

A série Poetamenos colocou em prática os axiomas do Plano-Pilôto para Poesia Concreta (1958), explorando cada um dos aspectos materiais expressos nos poemas. Além da espacialização dos poemas e de uma tipografia de ordem funcional sem elementos decorativos, o uso das cores veio promover um "campo mais amplo de significações ao poema e sugerir a possibilidade de múltiplas leituras, seguindo uma dada linha cromática ou um determinado espaço gráfico", que substancia a hermética da poesia concreta (Williams 1986: 12), por oposição ao espírito proclamado, pelos poetas de Noigandres: "o poema concreto é um objecto em e por si mesmo, não um intérprete de objectos exteriores e/ou sensações mais ou menos subjectivas" (Campos et al. 1956: 1).

A revolução de Poetamentos fez-se pela transposição para o campo da visualidade da melodia de timbres, "criando palavras, aglutinando e decompondo-as" (Khouri 2015), associando-as à semiótica da expressividade de cor. Assim, estes poemas são mecanismos de leitura que renunciam "à disputa do absoluto" em que a "comunicação mais rápida” (Campos et al. 1956: 2) é realizada numa medida inversa ao investimento realizado na leitura.

Esse investimento permite a descoberta e a aprendizagem da reflexividade característica da prática literária, identificando-se cada camada de significação, "num ciclo de retroalimentação algorítmica entre ler a escrita e escrever a leitura” (Cayley 2011; Howe) Cayley 2011, apud Portela 2017: 561). À medida que o leitor acede à experiência de ler cada poema re-escreve-o, desenvolvendo cognitivamente a sua compreensão sobre o texto "neste campo de forças de transações e interações" (Portela 2017: 562).

A leitura é assim uma viagem que "atravessa um campo de signos (...) criando suas próprias constelações lineares e multilineares" com múltiplos vetores, em que cada um "realiza uma interação de um comportamento ou estratégia particular e, deste modo, torna-se uma inscrição na superfície textual” (Portela 2017: 567; Portela 2013: 345-347). Assim, o poema funciona como um "mecanismo, regulando-se a si próprio" (Campos et al. 1956) iterativamente num ciclo de leitura e re-escrita em que o significado verbal e a materialidade interagem e se redefinem de forma constante (Portela 2003: 3).

As possibilidades de leitura na obra de Augusto de Campos surgem pelo trabalho e pela (re)aprendizagem da forma de ler em função do texto e da sua disposição. O domínio da sobre a forma textual e o trabalho para a quebra da opacidade do texto exploram os limites da legibilidade explorada na forma fanopaica. A transposição dessa forma não é imediata ao leitor inexperiente, mas permite sugerir o acesso à camada logopaica que se revelará progressivamente com a familiaridade do leitor para com as referências expostas no texto, bem como, se o leitor se desprender dos pré-conceitos, pela formulação melopaica que o irá guiar pelo sentido do texto.

A série poetamenos é simultaneamente um protótipo da poesia concreta que seria oficializada no final do ano de 1956, com a exposição nacional de arte concreta em São Paulo, como é um texto que dialoga com toda a história literária, dada a quantidade de 
referências encontradas pela leitura atomizada dos poemas analisados. Esse diálogo intertextual é sobretudo realizado com os autores identificados no paudeuma concreto: Mallarmé, Pound, Cummings, Joyce, Apollinaire, Webern, Boulez e Stockhausem, bem como os movimentos de vanguardas dos anos 20 interrompidas pela ascensão de regimes totalitários e da II Grande Guerra Mundial. Conhecendo o trabalho destas, agora, retaguardas, olhamos para Poetamenos como uma aplicação prática do Plano Pilôto para a Poesia Concreta de 1956.

A espacialização sintético-ideográfica de Apollinaire, a atomização e aglutinação de palavras de cummings, e sobretudo a lógica timbral de Webern que Mallarmé já antevira no seu "Un Coup de Des", através da sua tipografia funcional. Além disso Mallarmé reservara para cada estilo tipográfico do seu poema uma temática, tal como aqui em poetamenos as cores vão sendo associada a vários temas, concretos e histórico-sociais. poetamenos é a manifestação mallarmaica da greve e da recusa ao verso tradicional, iniciada com "os cinco sentidos" (1951-52), e de um sentido de inconformidade crítico que absorveu as vanguardas, transformando-as antropofagicamente em objectos poéticos de cariz lúdico-reflexivo que, como Marjorie Perloff apela em seu livro de 2010, é próprio de um unoriginal genious.

\title{
NOTAS
}

\begin{abstract}
* Tiago Santos (1984) é Licenciado e Pós-Graduado em Tecnologias de Informação Visual e Mestre em Design e Multimédia pela Universidade de Coimbra. Na mesma instituição frequentou o Doutoramento em Arte Contemporânea e actualmente é Doutorando do Programa de Materialidades da Literatura. Os seus interesses de investigação abrangem o branding, a tipografia, o design, a poesia concreta e a intermedialidade, investigando no presente momento a obra poética de Augusto de Campos do ponto de vista da arqueologia e expressividade da letra tipográfica. É membro do Centro Português de Literatura, Centro de Estudos Cinematográficos, Caminhos do Cinema Português e Associação Nacional de Designers. Adicionalmente tem colaborado em vários eventos promotores da cultura cinematográfica no âmbito da sua difusão, formação e produção.
\end{abstract}

\footnotetext{
${ }^{1}$ O poema viu a sua forma uniformizada em 1962 com o uso da tipografia "Futura Bold" (Campos 19: 105).

2 Posteriormente, três dos poemas integraram a "antologia" Noigandres 5, e a série completa foi editada em VIVA VAIA de 1979 (Aguilar 2004: 286). A segunda edição da série foi publicada em 1973 numa tiragem de 500 exemplares, financiada por Erthos A. de Souza (Campos 1973).
} 
${ }^{3}$ O poeta refere ainda "a representação monocolor q (sic.) está para o poema como uma fotografia para a realidade cromática", evidenciando as possibilidades abertas pela cor para a pluralidade de sentidos subsidiários visuais e sonoros.

${ }^{4}$ Comunicação pessoal de Manuel Portela (14 de Julho de 2019).

${ }^{5} \mathrm{O}$ discurso autodiegético manifesta-se com regularidade ao longo do corpus poético de Augusto de Campos sobretudo com uma temática reflexiva e introspectiva sobre a sua vida e obra

${ }^{6} \mathrm{O}$ número cinco pode ser interpretado como os cinco sentidos animais ou os cinco dedos de uma mão. A mão será a metáfora do acto de fazer e construir, neste caso, um forte onde os universos de Lygia e Augusto se possam encontrar e edificar um projecto conjunto.

${ }^{7}$ É forma transitiva na terceira pessoa singular do verbo latin dēdō. Em Português pode ser traduzido como 'se entregar', 'render', 'desistir' ou 'consignar'. Pode ainda ser traduzido como o acto de devoção a algo ou alguém, bem como de dedicatória.

${ }^{8}$ Lygia Azeredo e Augusto de Campos casaram a 3 de Julho de 1954. Esse facto permite ler, à luz da "Psicologia das Cores" de Eva Heller, que o azul e o violeta do poema, em conjunto, remetem para a fantasia do poeta com Lygia, culminando no par violeta e vermelho, isto é, o “sedutor”, o “imoral” (2015: 36, 51).

${ }^{9} \mathrm{O}$ swaddling é uma controversa técnica milenar de embrulhar os bebés para os manter quentes e os embalar no sono.

${ }^{10}$ Sta. Solange é uma santa cristã, do Séc IX, originária de Bourges, que ao consagrar a sua virgindade teve o poder de curar os doentes e exorcitar os demónios. A sua beleza conquistou Bernard de Gothie, filho do Conde de Pontiers, que não a conseguindo conquistar, a mandou raptar. Resistindo durante uma luta a cavalo com o seu raptor, estes caíram num riacho, sendo decapitada em cólera pelo seu raptor. O milagre desta Santa foi esta caminhar com a cabeça em suas mãos até à igreja mais próxima.

${ }^{11}$ A história intertextual de Augusto de Campos com Patrícia Galvão fez-se a partir do momento em que a poetisa publica "Natureza morta", sob o pseudónimo Solange Sohl, em 11 de agosto de 1948 no Diário de São Paulo. A partir daí Campos procurou resgatar a história e a "aura carismática que cercava o nome Pagu - "- a garota fatal e doidivanas que fez "vacilar o lar" de Tarsila - , a personalidade artística, literária e humana que hoje se reconhece nela" (Campos 2014: 13). O fascínio com a misteriosa autora de "natureza morta" leva-o a dialogar através do seu poema "O Sol por natural" de 1951.

12 "Sorella" é a palavra italiana para irmã.

${ }^{13}$ Em oposição à perspectiva egocêntrica e dialética descritiva presente nas cinco peças excluídas da primeira edição de John Donne (Campos 09: 128).

${ }^{14} \mathrm{~A}$ árvore da laranjeira por ter simultaneamente flores e frutos tornou-se um símbolo da fertilidade (cf. Heller 2015: 405).

${ }^{15} \mathrm{O}$ azul ciano e o laranja são cores complementares, anulando as temperaturas de cor, tornando a mensagem emotivamente neutra. 


\section{BIBLIOGRAFIA}

Aguilar, Gonzalo M. (2005), Poesia Concreta brasileira: as vanguardas na encruzilhada, Edusp, São Paulo, Brasil.

Amaral, Tatá / Filho, Francisco César (1986), Poema: Cidade, São Paulo, Brasil, Tangerina Filmes.

Bollobás, Enikő (2018), "Writing on the Margins of Sound and Sight: Augusto De Campos and Transnational Poetic Traditions", Americana E-Journal of American Studies in Hungary, 14(1). Obtido de http://americanaejournal.hu/vol14no1/bollobas-campos

Campos, Augusto (1956), "Pontos-periferia-poesia-concreta”, in Campos, Augusto / Pignatari, Décio / Campos, Haroldo (2014), Teoria da Poesia Concreta - textos críticos e manifestos 1950-1960, 5. ${ }^{a}$ ed., Cotia, São Paulo, Brasil, Ateliê Editorial.

-- (1966), “Da Antiode à Antilira”, in Campos, Augusto (2015), Poesia, antipoesia, antropofagia \& cia. (2. ${ }^{\text {a }}$ ed.), São Paulo, Companhia das Letras.

-- (1967), "Sem Palavras", in Campos, Augusto (2015), Poesia, antipoesia, antropofagia \& cia. (2. ${ }^{a}$ ed.), São Paulo, Companhia das Letras.

-- (1973), Poetamenos (2. ${ }^{a}$ ed.), Edições Invenção, São Paulo, Brasil.

-- (1994), “Dos textos teóricos”, Semiosfera : Humanidades-Tecnologías, Universidad Carlos III De Madrid, (2): 101-116.

-- (2009), Verso Reverso Controverso (2. ${ }^{a}$ ed.), Editora Perspectiva, São Paulo, Brasil

-- (2014), Pagu: vida-obra, São Paulo, Companhia das Letras.

Campos, Augusto/ Pignatari, Décio/ Campos, Haroldo (1956), Plano-pilôto para poesia concreta.

Campos, Raquel (2019), Entre vivas e vaias: a visualidade concreta de Augusto de Campos, (P. L. Z. Eyben, Ed.). Universidade de Brasília, Brasília, Brasil.

Cordeiro, Waldemar (1956), “O Objecto”, in Cordeiro, Analívia (Ed.), (2014), Fantasia Exacta (J. Norman, M. Shirasuna, \& I. Burbridge, Trans.), São Paulo, Itaú Cultural.

Eisele, Petra/ Ludwig, Annette/ Naegele, Isabel (Eds.) (2017), Futura: The Typeface, Londres, Laurence King Publishing. ISBN 978-17-8627-093-1

Erlhoff, M./ Marshall, T. (Eds.) (2011), Design Dictionary, Basel, Switzerland, Birkhäuser Verlag AG.

Hatherly, A. (1975), A Reinvenção da Leitura: Breve Ensaio Crítico Seguido de 19Textos Visuais, $138-152$.

Heller, E. (2015), A Psicologia das Cores - Como Actuam as Cores sobre os Sentimentos e a Razão, Madrid, Espanha, Editorial Gustavo Gili, S.A.

Hochuli, Jost (2009), Detail in Typography (S. Z. Verlag Niggli AG, Trans.), 2nd ed., London, Hyphen Press.

Ikonen, Teemu. (2003), Moving Text in Avant-Garde Poetry: Towards a Poetics of Textual Motion, Dichtung Digital, (4).

Khouri, O. (2015), A Poesia do Grupo Noigandres não nasce Concreta: torna-se. Ob- 
tido a 20 de Outubro de 2019, de http://www.nomuque.net/escritosdelisboa/ uncategorized/12-a-poesia-do-grupo-noigandres-nao-nasce-concreta-torna-se/

Mayer, Peter (1996), Concrete poems just are. Obtido a 20 de Fevereiro 14, de http://www. eyemagazine.com/feature/article/concrete-poems-just-are

Mitchell, Wade J. T. (2005), "There Are No Visual Media”, Journal of Visual Culture, 4(2), 257-266. http://doi.org/10.1177/1470412905054673

Neves, Juliana/ Geraldo Ferraz/ Patrícia Galvão (2005), A Experiência do Suplemento Literário do Diário de S. Paulo, nos anos 40. Annablume, FAPESP, São Paulo, Brasil

Plaza, Julio (2003), Arte e interatividade: autor-obra-recepção, ARS (São Paulo), 1(2), 0929. http://doi.org/10.1590/S1678-53202003000200002

Perloff, Marjorie (2010), Unoriginal Genius: Poetry by Other Means in the New Century, The University of Chicago Press, Ltd, Londres, Reino Unido.

Pondian, Juliana D. F. (2005), "Relações entre expressão e conteúdo na poesia concreta”, Estudos Semióticos, (1). http://doi.org/https://doi.org/10.11606/issn.1980-4016. esse.2005.49154

Portela, Manuel (2003), “Untranslations and Transcreations", Text,15, 305-320.

-- (2013), Script Reading Emotions. The Codex and the Computer as Self-Reflexive Machines. Londres, Inglaterra, The MIT Press.

-- (2017), "Scripts para Leituras Infinitas", in Caldeira, I./ Capinha, G./ Matos J. (orgs.), The edge of one of many circles: Homenagem a Irene Ramalho Santos. Vol. I. Imprensa da Universidade de Coimbra: Coimbra, Portugal

Shellhorse, A. (2017), Anti-Literature. The Politics and Limits of Representation in Modern Brazil and Argentina, University of Pittsburg Press. ISBN 978-0-8229-6447-6

Silva, Diogo (2008), "eis os amantes" de Augusto de Campos, in Portela, M. (org). DIGLITMEDIA - Literatura e Média na Era Digital. Obtido em 10 de Dezembro 2018 de http:// diglitmedia.blogspot.com/2008/12/eis-os-amantesde-augusto-de-campos.html

Solt, Mary Ellen (1971), Concrete Poetry: A World View, Londres, Reino Unido, Indiana University Press, Bloomington.

Süssekind, Flora/ Guimarães, Júlio (orgs.) (2004), Exposição Augusto de Campos - Poemas, Publicações, Manuscritos, Vídeos e Gravações, Rio de Janeiro, Fundação Casa de Rui Barbosa

Vasconcelos, Raíra (2015), "Poesia e Ideograma: Uma Leitura do Poema Eis os Amantes, de Augusto de Campos", Acta Semiotica Et Lingvistica (1), 77-86.

Williams, Bruce (1986), "poetamenos: Campo(s) de expressão em cores”, Mester, 14(1), $1-12$. 